\title{
Digital Platforms to Support Feeding, Physical Activity and Training by Cerebral Palsy
}

\author{
Ileana Hamburg \\ Institut Arbeit und Technik, WH Gelsenkirchen, \\ Munscheidstr. 14, D-45886 Gelsenkirchen, Germany \\ Gabriela Lütgen \\ Institut Arbeit und Technik, WH Gelsenkirchen, \\ Munscheidstr. 14, D-45886 Gelsenkirchen, Germany
}

\begin{abstract}
Cerebral palsy (CP) is one of the most common motor disability in rehabilitation, has antenatal antecedents and is often multi-factorial. Many people with CP are physically inactive, have difficulties with eating and drinking. The authors work together with organisations of people with disabilities, particularly people with $\mathrm{CP}$ to find solutions for improving Quality of Life (QoL) of these people. Within the Erasmus+ project CPWELLBEING the problems are connected with inclusive nutrition, physical activities and training by using interactive ICT platforms. The methods used in the project and the description of the developed training materials are presented in part 5 of this paper.
\end{abstract}

Keywords: Cerebral palsy, Inclusive Nutrition, Physical activity (PA), Training, ICT Platforms

\section{INTRODUCTION}

Cerebral palsy (CP) is s "a group of permanent disorders of the development of movement and posture, causing activity limitation, that are attributed to no progressive disturbances that occurred in the developing fatal or infant brain" (Rosenbaum, Paneth \& Leviton et al., 2007). CP is one of the most common motor disability in rehabilitation. The cause has been discussed since as chronic encephalopathy in children (Johnston, Moore, Quinn \& Smith, 2004).

In 1862, condition and abnormal delivery had been connected with obstetric misadventure. Epidemiological studies and brain imaging underline that CP frequently has antenatal antecedents and is often multi-factorial (Stanley, Blair \& Alberman, 2000).

It is estimated that 2 to 2,5 per thousand births in Europe has $\mathrm{CP}$ ( 1 per 500 persons = 1.000.000). CP cannot be cured, but persons can live a full life with proper care and supports, improving movements, intellectual development, level of communication and social relationships, improving their Quality of Life (QoL) according to the Convention on the Rights of Persons with Disabilities.

Nutrition and physical activity (PA) are closely linked with the QoL of persons with CP, especially with their physical and emotional wellbeing.

Many people with CP are physically inactive, some exercises are not possible, depending on the severity of cerebral palsy. But many health benefits may be achieved also by doing less than the recommendations. It is better to stick with a program than to do nothing (https://s3.amazonaws.com/academia.edu.documents/34183537/physical_activity_and_cerebral _palsy.pdf?). 
Eating and drinking are difficult for people with cerebral palsy. This is apparent soon after birth, with babies experiencing problems feeding either from the breast or bottle or may start later in life (https://www.cerebralpalsyguidance.com).

The authors work together with organisations of people with disabilities, particularly people with CP to find solutions for improving QoL of these people. Within the project Erasmus+ project CP-WELLBEING these problems are relate to nutrition, physical activities and training by using interactive ICT platforms. The methods used in the project and the description of the developed training materials are presented in part 5 of this paper.

\section{INCLUSIVE NUTRITON SUPPORT}

Many people with CP have less energy requirements in comparison with people without CP and these differences increase with increasing severity motor disabilities. Differences are also due to decreased basal metabolic rate (related to reduced lean body mass and adaptation to chronic poor nutrition) and of reductions in physical activity (PA) levels. Energy requirements of children and adolescents with severe $\mathrm{CP}$ who utilise a wheelchair for mobility have been are between 60 and 70\% of those of healthy typically developing children (Bjornson, Belza, Kartin \& McLaughlin, 2006), (Bjornson, Belza \& Kartin et al., 2007). Participation in PA including intense rehabilitation, increases the energy requirements of children with CP.

The mode of administration of nutritional support will depend upon the nutritional status of the person with CP and ability to consume adequate quantities of food and fluids orally, and the risk of pulmonary aspiration.

Cerebral palsy can affect the muscles that open and close the mouth and move the lips and the tongue. Some people with cerebral palsy have difficulties in chewing and swallowing food and drink - a condition known as dysphagia. Cerebral palsy often impacts fine motor skills, what can affect the ability of people to easily use cutlery, hold a cup, or transfer food from a plate to their mouth using their hands.

Others suffer from gastroesophageal reflux - where acid from the stomach rises into the oesophagus - and this makes eating uncomfortable or painful but can sometimes be controlled by medication.

It is recommended that first-line treatment involve oral nutritional support including adequate positioning and physical support during meal times. Some children with $\mathrm{CP}$ have their eating position but additional body and head support are required to keep them stable and comfortable, and to ensure they swallow safely.

Adaptive feeding equipment could be used to support encourage independence by assisting children to self feed. Thickness of fluids can be modified, if the therapist recommends it to ensure airway safety, maximise eating efficiency and reduce fatigue during mealtimes. Smaller more frequent meals can also useful.

If no specific recommendations for use in individuals with $\mathrm{CP}$, standard recommendations for dietary of vitamins, minerals and trace elements should be utilised. Inadequate dietary may be addressed through the inclusion of foods rich in the micronutrient at risk or through supplementation (Johnston, Moore, Quinn \& Smith, 2004).

\section{PHYSICAL ACTIVITIES}

One problem is that children and adolescents with CP experience participation restrictions and 
limitations in physical activity. PA have been defined as all body movements resulting in an increased energy output from the resting position. Children and adolescents with CP show lower levels of PA compared to healthy people. Lower levels of PA contribute to reduced physical fitness, which may increase the risk of developing secondary health problems such as pain and fatigue, cardiovascular disease and diabetes mellitus later in life. PA is assumed to have a positive relation with health related quality of life and psychosocial functioning (Claassen, Gorter, Stewart, Verschuren, Galuppi \& Shimmell, 2011).

Physical activity is very important for persons with CP and they can participate in physical activity even though they have less endurance and execute reduced physical exercises compared to children without CP. The benefits of physical activity and exercises to overall health are well known, especially to people with disabilities who are less likely to engage in physically healthy lifestyles compared to people without disabilities. Inactivity of adults with $\mathrm{CP}$ could increase severity of disease and reduced overall health and well-being (Rimmer, 2005). Weakness make it difficult for children with CP to participate in sport and play activities at necessary level of intensity sufficient to develop and maintain normal physical fitness levels. So it is needed to identify effective methods to improve physical fitness for this group and encourage it.

The Centre for Disease Control and Prevention (CDC) have concluded that daily participation in developmentally appropriate, moderate to vigorous physical activity lasting 60 minutes or longer can reduce body fat, encourage weight loss, and improve aerobic fitness in youth aged 6 to 18 years without disabilities (Strong, Malina \& Blimkie et al., 2005). Some studies suggest that association exist between physical activity and various indexes of mental health, including anxiety, depressive symptoms and physical self-concept.

\section{TRAINING AND INCLUSIVE EDUCATION ISSUES}

Training and education are important issues also in CP people future lives. There are the keys that open the door to all future opportunities. Things which CP people are able to do later are also a result of what they have learned as children. The objectives of the training and education the child receives the skills that he learns, the kind of focus of own education is quite important, both in the short and long term. If the child's training and education is aimed at giving him or her the ability to live independently, the skills that help him to follow a career may be cut short (http://cerebralpalsy-educationandsociety.com/?).

The early years of training usually bring changes also for children with CP. In between the ages seven and twelve, a child's rate of physical improvement has levelled off in areas such as balance and coordination, and it is generally considered as a good point in the child's life to refocus their efforts from physical improvement and toward intellectual learning and growth. Children without disabilities are encouraged to concentrate more on academics and less on play, but for the child with $\mathrm{CP}$ these years usually involve learning to be independent with an adapted level of physical function.

It is important to consider many factors when choosing a training/ education environment for the child. The child needs to be in an environment where can leave and learn without being overly frustrated. For children with $\mathrm{CP}$ is important to interact with children without disabilities, and it is necessary to be in an appropriate training environment.

Many children with $\mathrm{CP}$ have also learning disabilities i.e. have a less average level of intelligence or have difficulty processing certain types of information. Or it is possible that 
having a learning disability, children with CP are limited in their ability to communicate. In this case teachers may not be able to tell whether or not the child understands the lesson if they are unable to speak. So many children with CP are sent to special education programs, focussed on different therapies, not to academic progress. Digital technologies can sometimes help to include such children in inclusive educational environments (http://cerebralpalsyeducationandsociety.com/?).

„Inclusive education is a process of strengthening the capacity of the education system to reach out to all learners. As an overall principle, it should guide all education policies and practices, starting from the fact that education is a basic human right and the foundation for European countries at the beginning; qualified teachers and social workers, methodology are missing (European Commission, 2014).

The use of digital technologies in inclusive education requires many sectors of expertise and activities (European Agency, 2014) like stakeholders input and views, training of education professionals an- $\mathrm{d}$ of ICT developers. Some principles to be taken into consideration in digital technology for inclusive education are (Hamburg \& Bucksch, 2016):

- An active involvement of learners with disabilities, their families/representatives in the development and use of ICT.

- Implementation and evaluation with users of services which facilitates learners access to digital technologies.

- The provision of ICT in education of people with disabilities to be aligned with the goals of inclusive education and should be available for formal, informal, blended, social and other forms of learning.

- The implementation of ICT in inclusive education should take a systemic approach.

Inclusive education is not always applied particularly for children with CP. Due to a common misconception of intelligence levels and cognitive ability among children with cerebral palsy, it is important that professionals help to assess child's specific deficiencies, educational strengths and needs.

Learning difficulties can be sometimes detected in the pre-school or early school years and are in connection with other problems of children with CP like visual-perception disorders or language disorders. Sometimes, a child with light CP develop learning disabilities later. Sending the child in an inclusive class room could help to minimize learning disabilities, or even avoid them completely and support learning progress.

It is important that chosen form of education fits the child and that the parents support the child and listen to the problems. It is important to help the child understand that it is not the child fault. Keeping the child's positive image of themselves alive and well will help them to succeed in every facet of life.

\section{EXAMPLE}

Inclusive nutrition and physical activity particularly for people with $\mathrm{CP}$ are not fully implemented in Europe due to a lack of:

- awareness and knowledge of parents and professionals about the effectiveness of inclusive feeding techniques from the earliest ages of life

- Feeding ability of many adults with CP who have not been adequately supported in its childhood. They are not sufficiently aware

- and trained on the possibilities for accessing to a healthy and satisfying feeding and accessible tools at their disposal 
- awareness and understanding of the impact on the emotional well-being of feeding aggressive techniques usually employed and the importance of food as an element of pleasure and exercise of rights

- initiative and knowledge of PCP and families regarding their participation in inclusive physical activities, alternatives and opportunities missing adequate training supported by ICT Platforms.

The Erasmus+ project CP-WELLBEING (www.cp-well.eu) is launched with the main objective of increasing the competences (attitudes, skills, knowledge) of persons withCP, families and professionals about how to implement inclusive feeding and physical activity with a global Wellbeing and QoL approach, through an innovative training program. The project partners come from 5 European countries: Spain, Portugal, Italy, Croatia and Germany and are organisations which work with CP people and research/education institutions.

\section{The project has some specific objectives:}

- To raise awareness and motivate the full collective about the importance of inclusive feeding and Physical activity as a tool for improving QoL of PCP.

- Transfer knowledge, tools and guidelines to parents of children with CP and professionals to enable inclusive feeding and integrative physical activity from the earliest stages of life

- To transfer knowledge, tools and guidelines for adults with $\mathrm{CP}$, families and professionals,

- regarding inclusive feeding and physical activity

\section{The following results have been obtained until now:}

- Co-Created Methodological Guide will be developed, with the direct participation of End Users, with the main objective of

- Determining the key contents, methodologies and tools

- Training Materials addressed to persons with CP, families and professionals for facilitating the implementation of inclusive feeding and integrative and adapted physical activity.

- Designed Experiential Training Activities addressed to persons with Cerebral Palsy, families and professionals for facilitating the implementation of inclusive feeding and integrative and adapted physical activity.

- Development of an ICT Platform to support training.

In the following we will describe the Training Platform, for supporting the implementation of Training Materials and Designed Experiential Training Activities. The responsibility for the development of the platform have the authors.

The platform gives information about the project and experiences of project partners within their workshop activities with people with $\mathrm{CP}$, trainers, professionals and parents. The topics of the workshops were Inclusive Nutrition and Physical activities (Figure 1). 


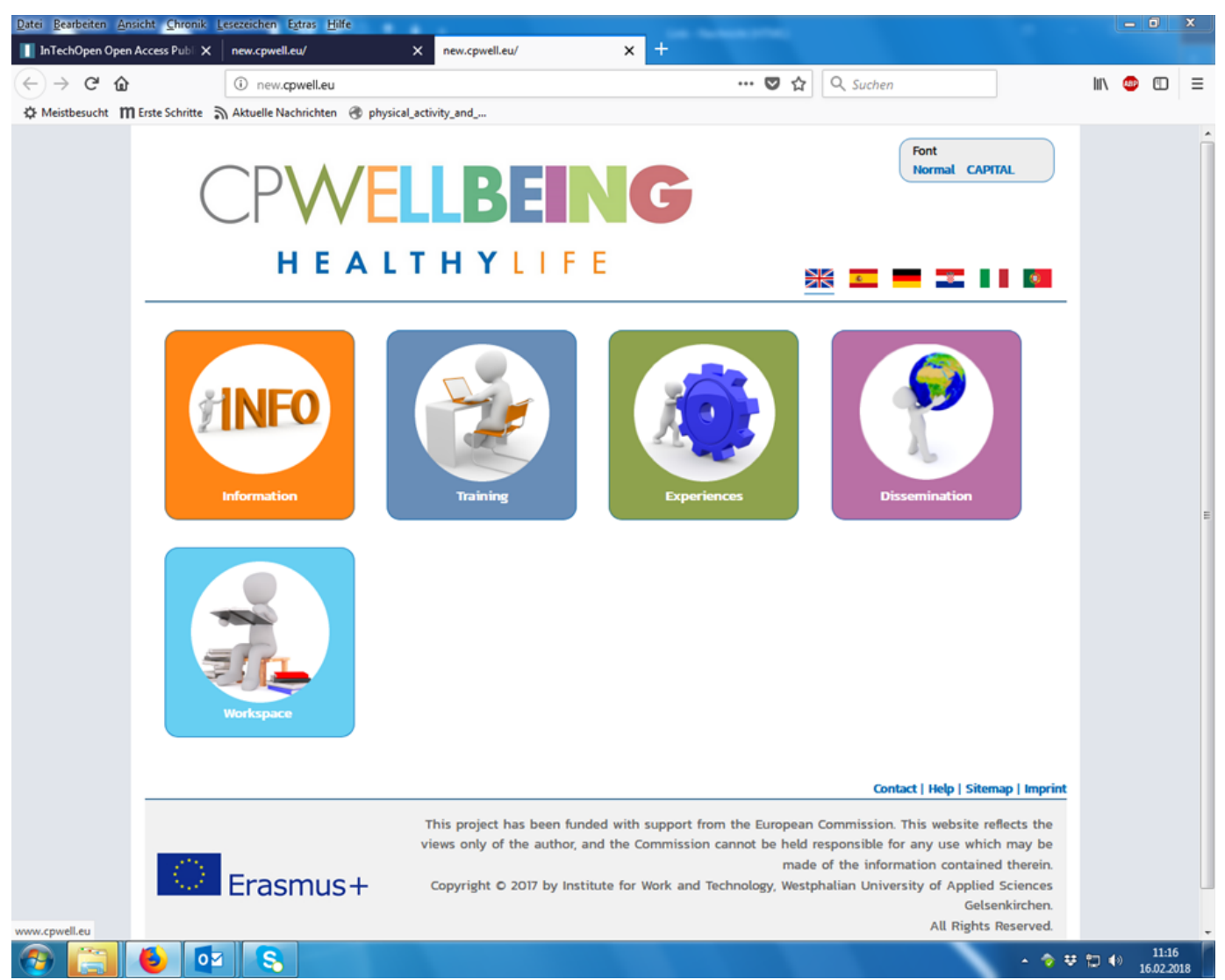

Figure 1: Main page of the platform ((www.cp-well.eu)

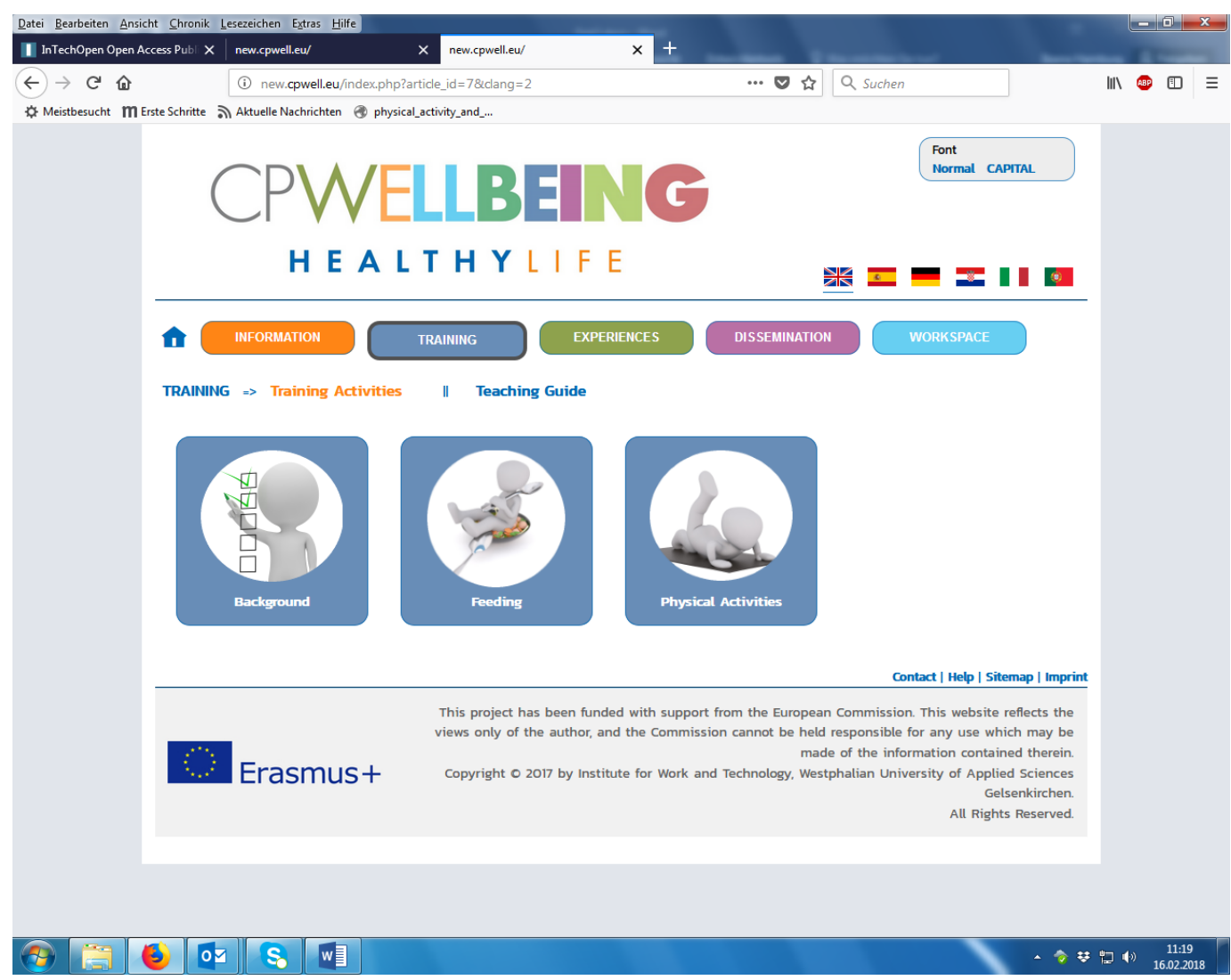

Figure 1: Training activities (www.cp-well.eu)

Three groups of Training activities have been held and documented on the platform with the topics of General knowledge about CP - Background, Inclusive Nutrition - Eating and Physical Activity. Training material including the steps of workshops and an execution guide are 
available in all partner languages on the platform (Figure 2).

A detailed manual for trainers - Teaching Guide is also available in partner languages (Figure 3).

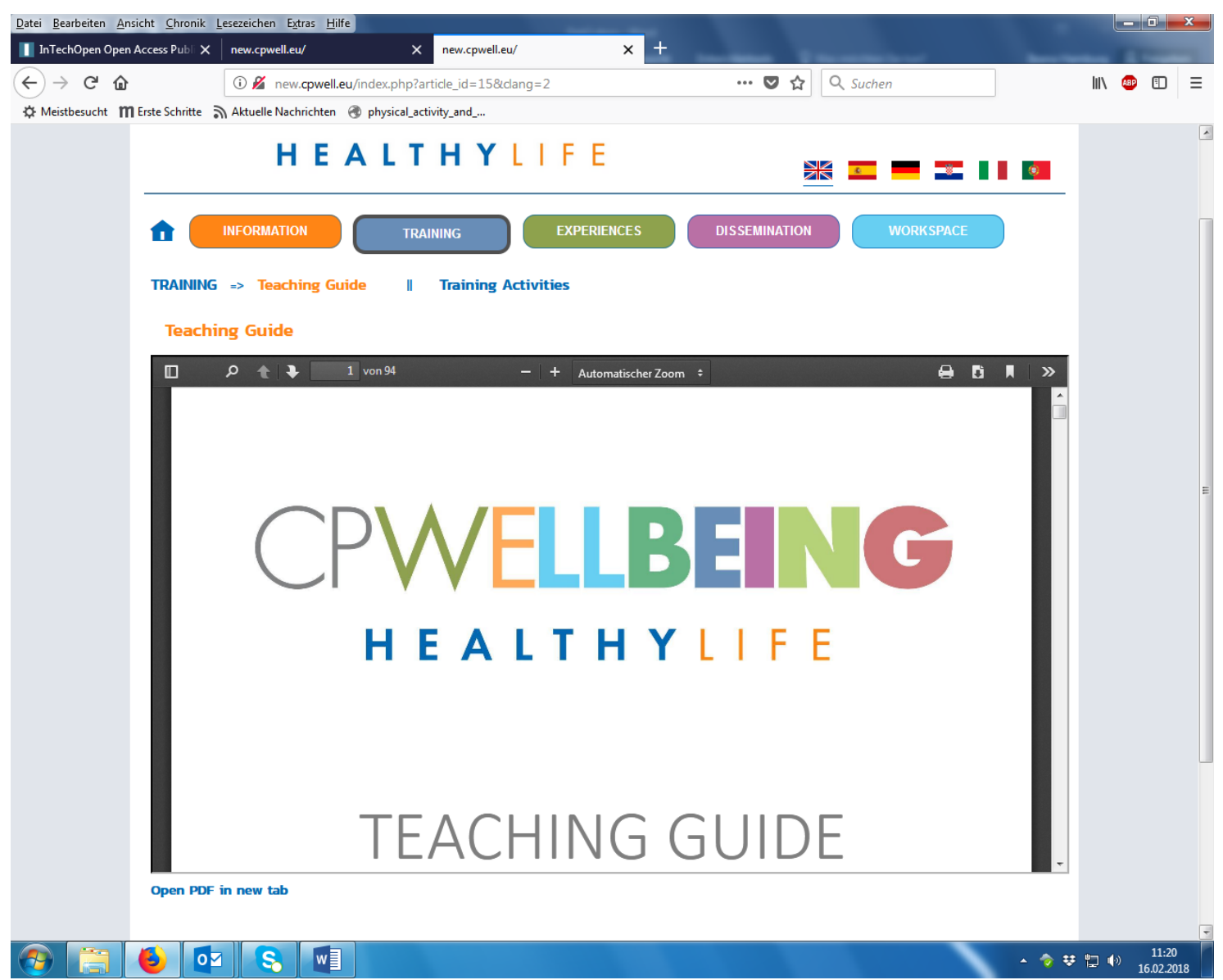

Figure 3: Teaching Guide (www.cp-well.eu)

The interaction trainer, trainee, parents takes place within an area which is protected by corresponding password. The trainer can organize the work with trainees: use the existing saved documents, upload new ones, as well as exercises for the trainees. The trainees can use the uploaded documents and upload their homework. The platform shows the results of their homework (Figure 4). 
Homework Training Activity 1

Quality of Life interview

1. What are the habits of your daily life that you follow to take care of your health?

Annex of healthy habits in eating and physical activity. ${ }^{[1]}$
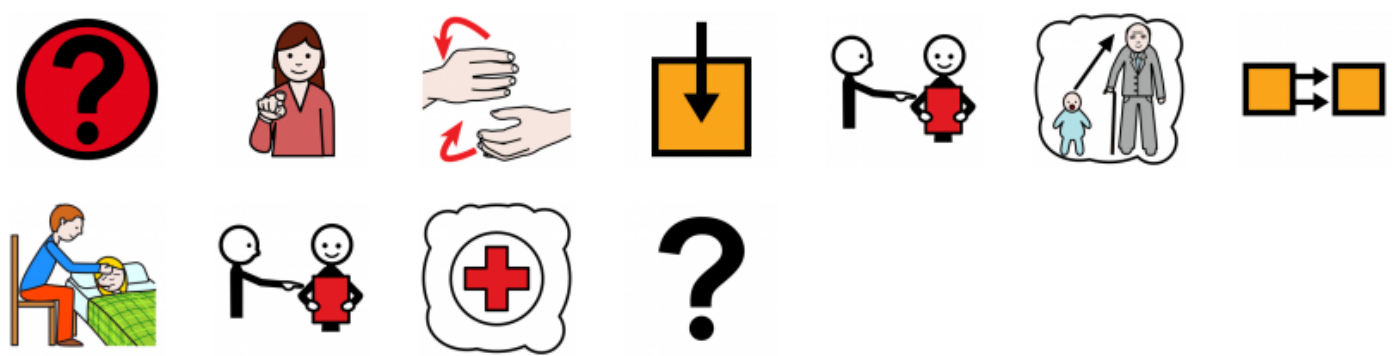

Please enter your answer

2. How do you participate in carrying out those habits? ${ }^{[2]}$
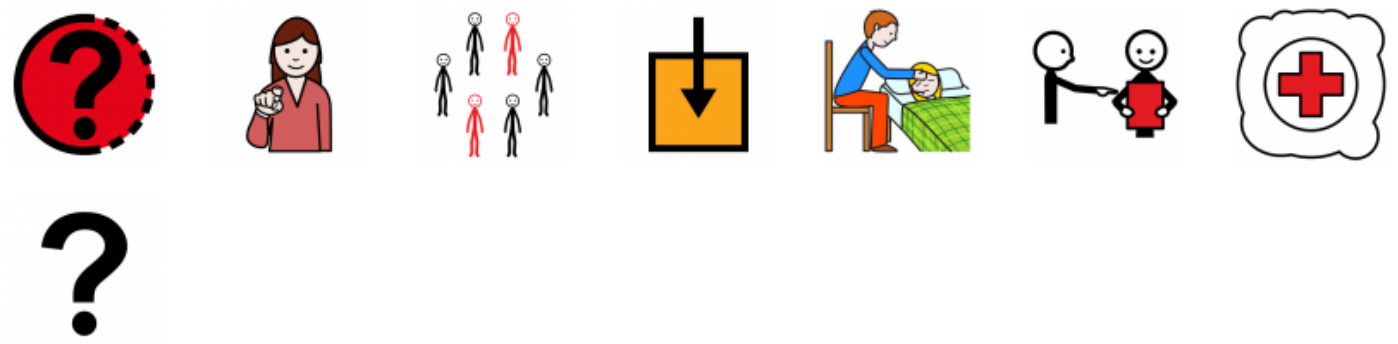

Please enter your answer

Figure 4: Homework (www.cp-well.eu)

\section{CONCLUSIONS}

Some children and adults i.e. with $\mathrm{CP}$ experience difficulties and require access to and utilization of considerable health care resources and ICT support over time. Many children with this development disorder have nutrition and physical problems and also intellectual impairments. The primary objective of the described project was to help them, the trainers and parents to minimize the difficulties by corresponding training and exercises.

\section{ACKNOWLEDGE}

The paper describes objectives and outputs of the European Erasmus+ project CP-WELLBEING.

\section{References}

Bjornson, K.F., Belza, B., Kartin, D., et al. 2007. Ambulatory physical activity performance in youth with cerebral palsy and youth who are developing typically. Phys Ther, 87. pp. 248-257.

Bjornson, K.F., Belza, B., Kartin, D., McLaughlin, J. 2006. Ambulatory activity in youth with cerebral palsy. Dev Med Child Neurol. pp.48-20.

Claassen, A.O.M., Gorter, J.W., Stewart, D., Verschuren, O., Galuppi, B.E., Shimmell, L.J. 2011. Becoming and staying physically active in adolescents with cerebral palsy: protocol of a qualitative study of facilitators and barriers to physical activity. BMC Pediatrics 11.pp. 1471-2431. 
Hamburg, I., Bucksch, S. 2016. Inclusive educational technology. In: Archives of business research 4, no. 1, p. 27-35 Johnston, T.E., Moore, S.E., Quinn, L.T., Smith, B.T. 2004. Energy cost of walking in children with cerebral palsy: relation to the Gross Motor Function Classification System. Dev Med Child Neurol 46. pp. 34 -38.

Kerr Graham, H., Selber, P. 2003. Musculoskeletal aspects of cerebral palsy. J Bone Joint Surg Br 85. pp. 157-166.

Rimmer, J.H. 2005. The conspicuous absence of people with disabilities in public fitness and recreation facilities: lack of interest or lack of access? Am J Health Promot 19. pp. 327-329.

Rosenbaum, P., Paneth, N., Leviton, A., et al. 2007. A report: the definition and classification of cerebral palsy April 2006. Developmental Medicine \& Child Neurology. February 109. pp. 8-14.

Rotta, N.T. 2002. Cerebral palsy, new therapeutic possibilities. J Pediatr (Rio J) 78 Suppl 1. pp. 48-54.

Stanley, F., Blair, E., Alberman, E. 2000. Cerebral Palsies: Epidemiology and Causal Pathways, Vol. 151. Cambridge University Press, Cambridge.

Strong, W.B., Malina, R.M., Blimkie, C.J., et al. 2005. Evidence based physical activity for school-age youth. J Pediatr, 146. pp. 732-737. 